\title{
Evaluation of Non Crystalline Phase in AZS Refractories by XRD Methods
}

\author{
M. S. Conconi ${ }^{1,2,3}$, N. M. Rendtorff ${ }^{1,3,4}$, E. F. Aglietti ${ }^{1,4,5}$ \\ ${ }^{1}$ CETMIC (Centro de Tecnología de Recursos Minerales y Cerámica, (CIC-CONICET-CCT La Plata)), M. B. Gonnet, Argentina; \\ ${ }^{2}$ Facultad de Ingeniería de la Universidad Nacional de La Plata. Argentina; ${ }^{3}$ CIC-PBA, Buenos Aires Argentina; ${ }^{4}$ Facultad de \\ Ciencias Exactas de la Universidad Nacional de La Plata. Argentina; ${ }^{5}$ CONICET La Plata, Argentina. \\ Email: rendtorff@cetmic.unlp.edu.ar
}

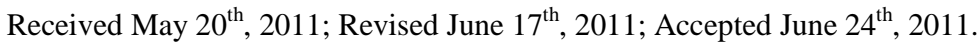

\begin{abstract}
The relation between the atomic structure and the macroscopic properties and behaviors of a material constitute one of the objectives of the materials science, particularly in the design and development of ceramic materials. Crystalline and non crystalline phases together with pores, grain boundaries, etc. affect mechanical and fracture prop-erties as well as chemical resistance and electric properties. These aspects will be bonded to the raw materials chosen and the whole processing route. In glass industry, although there are other electrofused refractories such as the alumina ones used in the feeding of the fusion kilns, probably the most used refractories in contact with the melted glass are electrofused materials that belong to the $\mathrm{Al}_{2} \mathrm{O}_{3}-\mathrm{SiO}_{2}-\mathrm{ZrO}_{2}$ system commonly named AZS. Exceptionally for refractory materials the amount of the glassy phase in a AZS material is important and appreciable; and makes them particularly adequate for containing fussed glass. The glass proportion will define much of their prop-erties and behaviors. In the present work the results of the non crystalline phase quantification of two samples of commercial AZS materials are presented and compared. These were obtained by three different methods using in the X ray powder diffraction $(X R D)$ techniques. The first method consists in the linear interpolation of the base lines of the diffractograms compared to the amorphous silica and the fully crystalline quartz. The other two methods are based in the application of the Rietveld method. One is the internal standard method with quartz as fully crystalline standard and the other one consist in the inclusion of the glassy phase to the refinement with a structural model that can be understood as the widening of the peaks consequence of an extreme decrease in the crystallite size of a quartz phase. The three methods showed equivalent results (with differences less than 3\%) for the two samples and demonstrated that are adequate for the quantification of the non crystalline phase in this kind of materials.
\end{abstract}

Keywords: XRD, Rietveld Method, Non Crystalline Phase, Refractories

\section{Introduction}

In glass industry, although there are other electrofused refractories such as the alumina ones used in the feeding of the fusion kilns, probably the most used refractories in contact with the melted glass are electrofused materials that belong to the $\mathrm{Al}_{2} \mathrm{O}_{3}-\mathrm{SiO}_{2}-\mathrm{ZrO}_{2}$ system commonly named AZS.

In glass industry, although there are other electrofused refractories such as the alumina ones used in [1,2]. These materials have influenced drastically the quality levels and productivity of the glass fabrication processes [3]. The first advance achieves by these materials was the improvement in the corrosion resistance, increasing the life of the kilns, together with the quality of the processed glass. Other important progresses accomplish were the improvement in the mounting time and decrease in the devitrification cords and lower amount of bubbles produced by the "blistering" process [4-6].

Exceptionally for refractory materials the amount of the glassy phase in a ASZ material is important and appreciable; The weight proportions is around $20 \%$ and makes them particularly adequate for containing fussed glass. The glass proportion will define much of their properties and behaviors.

To validate and compare three quantification methods for the non crystalline phase of an electrofused refractory material is the principal objective of the present work. In the materials field the use of the $\mathrm{X}$ ray diffraction technique for the non crystalline or amorphous fraction quan- 
tification is a permanent challenge that has been studied from diverse forms. Three of them are compared in the present work.

The typical composition of an AZS material of the normal filling cast type, from the supplier information is shown in Table 1.

Ohlberg [7] developed a method for determining the crystallinity percentage (C\%) in partially devitrified glasses, by the interpolation of the base line of the diffractogram between the corresponding to amorphous silica and fully crystalline quartz.

$$
C \%=100 \times \frac{\left(I_{g}-I_{\mathrm{m}}\right)}{\left(I_{g}-I_{c}\right)}
$$

Where $I_{g}, I_{m}$ y $I_{c}$ are the diffractogram intensities at $2 \theta$ $=22.5^{\circ} \mathrm{C}$ corresponding to a sample $100 \%$ glass (amorphous silica), the partially crystalline phase (problem sample) and the $100 \%$ crystalline standard (quartz) respectively.

This equation commonly utilized for determining crystallinity in vitro-ceramic materials in a wide range of proportions $[8,9]$, it could be valid to assume that the amorphous or non crystalline $\left(\mathrm{NC}_{\mathrm{O}} \%\right)$ proportion can be obtained from the following equation defining $\mathrm{NC}_{\mathrm{Oh}} \%$ as a complement of the crystallinity $(N C \%+C \%=100)$.

$$
N C_{O h} \%=100-C \%=100 \times \frac{1-\left(I_{g}-I_{\mathrm{m}}\right)}{\left(I_{g}-I_{c}\right)}=100 \times \frac{\left(I_{c}-I_{\mathrm{m}}\right)}{\left(I_{g}-I_{c}\right)}
$$

The Rietveld method [10,11] has demonstrated to be an effective tool for quantitative phase analysis in diverse materials $[12,13]$. The quantitative analysis is carried out from the scale factors refined for each phase (Si) according to the following equation:

$$
W_{i}=\frac{S_{i}(Z M V)_{i} / \tau_{i}}{\sum_{p} S_{p}(Z M V)_{p} / \tau_{p}}
$$

Table 1. Typical compositions of an electrofused AZS refractory.

\begin{tabular}{cccc}
\hline $\begin{array}{c}\text { Chemical } \\
\text { composition }\end{array}$ & (\% wt.) & $\begin{array}{c}\text { Mineralogical } \\
\text { composition }\end{array}$ & (\% wt.) \\
\hline $\mathbf{Z r O}_{2}+\mathbf{H f O}_{2}$ & 35.4 & $\mathbf{m}-\mathrm{ZrO}_{2}$ & 33.0 \\
$\mathbf{A l}_{2} \mathbf{O}_{3}$ & 48.0 & $\mathbf{A l}_{2} \mathbf{O}_{3}$ & 47.0 \\
$\mathbf{S i O}_{2}$ & 15.2 & Amorphous phase & 20.0 \\
$\mathbf{N a}_{2} \mathbf{O}$ & 1.5 & & \\
$\mathbf{T i O}_{2}$ & 0.04 & & \\
$\mathbf{F e}_{2} \mathbf{O}_{3}$ & 0.04 & & \\
\hline
\end{tabular}

a. http://www.sefpro.com/fused-cast-azs.aspx
Where Wi is the weight fraction of the i-phase over all the present phases. $\mathrm{Si}, \mathrm{Zi}, \mathrm{Mi}, \mathrm{Vi}$ and $\tau \mathrm{i}$ are the scale factor, the number of molecules per unit cell, the mo lecular weight, the unit cell volume and the mass-absorption correction factor of the particles for the i-phase, respect tively.

In the Rietveld analysis, the crystalline structure of each phase in the sample should be known. Hence this method does not allow including the amorphous or non-crystalline phases. However several authors had put into practice the quantification of these phases using the Rietveld refinement in efficient way. De la Torre applied the method for samples with the aggregate of a fully crystalline (100\%) internal standard in a known proportion, and determined the experimental conditions which affect the uncertainty of the amorphous phase determination using different internal standards [14].

Le Bail demonstrated that it is possible to include the silica glass in the Rietveld refinement through a structural model with crystalline defects [15]. Lutterotti [16] applied Le Bail method for the silica glass introducing defects from the crystal size for reproducing the peak widening; verifying this method for standard samples of quartz and amorphous silica, after he applied it to sanitary ceramic and to a AZS refractory. Finally Ward [17] compared two Rietveld methods in flaying ashes. The first one with the internal standard aggregate in known proportion and other one introducing the amorphous phase in the refinement program through the incorporation of experimental standards of non crystalline phases like meta-caolin or tridimite.

Mechanical mixtures of crystalline and non crystalline had been commonly used as standards for studying the efficiency of non crystalline quantification methods.

In electrofused or sintered materials, these mixtures are not the most adequate, due to the fact that the phase distribution in the standards differs from the actual studied materials.

In the first case crystalline and non crystalline particles are clearly differentiated and produce different diffractions compared to the produced in samples with particles where both type of phases are together in the same particle. In consequence the comparison of diverse methods with samples with unknown amorphous content will allow validating them.

In the present work the results of the non crystalline phase quantification of two samples of commercial AZS materials are presented and compared. These were obtained by three different methods based in the $\mathrm{X}$ ray powder diffraction (XRD).

The redefinition of the Ohlberg equation (Equation 2) was used for the first method. Milled quartz $\left(\mathrm{SiO}_{2}\right)$ was 
used as fully crystalline standard for the first Rietveld refinement method. Finally the Le Bail model based method was applied with the amorphous phase incorporated as a nanocrystalline material with a $\beta$-Carnegieite structure.

\section{Experimental Procedures}

The analyzed material consisted in a monolithic electrofused commercial AZS refractory normal filling type (AZS ER 1681 RN, Saint-Gobain SEFPRO, Italy). Particularly two samples (AZS1 y AZS2) of the material were studied coming from different blocks. For the analysis samples were milled in Agatha mortar up to mesh 100.

The chemical analysis of the samples was carried out by Atomic Emission Spectroscopy by inductive coupled plasma (Varian Vista AX CCD Simultaneous ICP-AES) with the exception of the zirconium which was done by $\mathrm{X}$ ray Fluorescence (Shimadzu EDX800HS).

For the amorphous phase characterization Silicon dioxide $\left(\mathrm{SiO}_{2}\right)$ powder was used as standard (Carlo Erba RPE) for obtaining $I g$ in the Ohlberg method and for refining the pure glassy phase in the Rietveld Method. Also $15 \%$ wt. of milled quartz was used as internal standard aggregate before the Rietveld quantification. This was chosen because it presents a similar absorption coefficient to the sample [14]. For obtaining the Ic The same crystalline quartz was used.

Materials were analyzed by XRD (Philips 3020 equipment with $\mathrm{Cu} \mathrm{K} \alpha$ radiation in Ni filter at $40 \mathrm{kV}$ to $20 \mathrm{~mA}$ ). Difractograms were carried out between 10 and 70 in $2 \theta$ with 0.04 steps of 3 seconds.

The powder XRD patterns were analyzed with the program FullProf [18], which is a multipurpose profile-fitting program, including Rietveld refinement. The starting crystallographic data for each phase were extracted from the literature.if any non crystalline phase is present in the sample when the Rietveld refinement done, the internal standard content would be overestimated. The percentage of amorphous phase in the sample without the aggregated standard can be calculated using the following equation [14]:

$$
N C_{I S} \%=\frac{\left(1-W_{s} / R_{s}\right)}{100-W_{s}} \times 10^{4} \%
$$

Where $N C_{I S} \%$ is the non crystalline content by the internal standard method, $W_{S}$ is the internal standard proportion aggregated (\%) and $R_{S}$ is the internal standard evaluated by the Rietveld method.

For obtaining the actual phase content of each present phase they should be corrected by the amorphous phase evaluated.
The only refined parameter in the Le Bail model refinement was the scale parameter. For the other phases scale factor was accompanied by the cell parameters, and the rest of the parameters which describe the profile. The background was calculated from the interpolation of several $2 \theta$ : intensity pairs. Moreover the background was not refined between $5^{\circ}$ and $45^{\circ}$, while in the rest of the diffractogram they were refined with the other of the parameters.

Before introducing the non crystalline phase in the refinement of the studied samples, the pure amorphous silica was analyzed for determining the crystalline and profile parameters.

\section{Results and Discussion}

The results of the chemical analysis of the samples are presented in Table 2. The $\mathrm{ZrO}_{2}$ content was calculated from the elemental $\mathrm{Zr}$ content obtained by XRF.

In the XRD test $\mathrm{Al}_{2} \mathrm{O}_{3}$ together with monoclinic and tetragonal zirconia were detected. There were not detected any Silicon ( $\mathrm{Si}$ ) containing crystalline phase, evidencing an important silica rich ( $\geq 70 \%)$ non crystalline phase. This fact supports the assumption of approximating the non crystalline phase of these materials with silica glass.

\subsection{Ohlberg method}

In order to apply Ohlberg equation (Equation 2) the corresponding intensities of the diffractograms at $2 \theta=22.5$ for both samples AZS1 and AZS2. Both samples presented almost identical intensities, in Figure 1 a detail of the superposed diffractograms for AZS1 sample, the amorphous silica and crystalline quartz between $15^{\circ}$ and $35^{\circ}$ is shown and in Table 3 the results of the amorphous quantification of both samples are revealed.

\subsection{Internal Standard Method}

In Figure 2 the diffractogram with its corresponding refinement curve is shown for sample AZS2 with the $15 \%$ wt. quartz aggregate. There it can be observed the experimental profile (dots) and the theoretical profile (continuous), the corresponding positions of the diffraction lines of each phase (alumina, monoclinic zirconia, quartz and tetragonal zirconia respectively) are expose in vertical bars, finally the difference between the observed profile and the theoretical profile is shown in the base of the graph.

After the Rietveld refinement the quartz evaluated content was 19.1\%wt. in AZS1 and 19.2\%wt in AZS2. The actual contents of non crystalline and crystalline phases by this method are shown in Table 4 . The evaluated crystalline and non crystalline content for the two different samples are equivalent.

Table 2. Chemical composition of the studied materials. 


\begin{tabular}{ccc}
\hline Chemical & \multicolumn{2}{c}{ Sample } \\
\cline { 2 - 3 } Composition $^{\mathrm{a}}$ & $\mathrm{AZS} 1$ & AZS2 \\
\hline $\mathrm{SiO}_{2}$ & 15.4 & 14.7 \\
$\mathrm{Al}_{2} \mathrm{O}_{3}$ & 45.9 & 45.9 \\
$\mathrm{Fe}_{2} \mathrm{O}_{3}$ & 0.33 & 0.42 \\
$\mathrm{CaO}$ & 0.10 & 0.12 \\
$\mathrm{MgO}$ & 0.02 & 0.02 \\
$\mathrm{Na} 2$ & 1.29 & 1.28 \\
$\mathrm{~K}_{2} \mathrm{O}$ & 0.03 & 0.03 \\
$\mathrm{TiO}_{2}$ & 0.08 & 0.04 \\
$\mathrm{ZrO}_{2}+\mathrm{HfO}_{2}$ & 32.4 & 32.3 \\
\hline
\end{tabular}

a:ICP and XRF results

Table 3. Non crystalline content evaluated by the Ohlberg method (Equation 2).

\begin{tabular}{cc}
\hline Sample & $\mathrm{NC}_{\boldsymbol{O h}} \%$ \\
\hline AZS1 & 23.3 \\
AZS2 & 23.2 \\
\hline
\end{tabular}

Table 4. Quantitative analysis results from the Rietveld Method, with internal Standard.

\begin{tabular}{ccc}
\hline Phase & $\begin{array}{c}\text { AZS1 } \\
\text { (\%wt.) }\end{array}$ & $\begin{array}{c}\text { AZS2 } \\
\text { (\%wt.) }\end{array}$ \\
\hline $\mathbf{A l}_{2} \mathbf{O}_{3}$ & 46.5 & 47.3 \\
$\mathbf{m}-\mathbf{Z r O}_{2}$ & 27.8 & 26.8 \\
$\mathbf{t}-\mathbf{Z r O}_{2}$ & $\approx 1$ & $\approx 1$ \\
$\mathbf{N C}_{I S} \%$ & 24.7 & 24.9 \\
\hline
\end{tabular}

Table 5. Quantitative analysis results from the Rietveld Method by Le Bail model.

\begin{tabular}{ccc}
\hline Phase & $\begin{array}{c}\text { AZS1 } \\
\text { (\%wt.) }\end{array}$ & $\begin{array}{c}\text { AZS2 } \\
\text { (\%wt.) }\end{array}$ \\
\hline $\mathrm{Al}_{2} \mathbf{O}_{3}$ & 48.1 & 42.9 \\
$\mathbf{m}-\mathrm{ZrO}_{2}$ & 28.0 & 30.3 \\
$\mathbf{t}-\mathrm{ZrO}_{2}$ & $\approx 1$ & $\approx 1$ \\
$\mathbf{N C}_{\boldsymbol{L} \boldsymbol{B}} \%$ & 22.9 & 25.8 \\
\hline
\end{tabular}

Figure 3 presents de Rietveld refinement figure using the Le Bail model in sample AZS1 made with the method described before. Diffraction lines correspond to: Alumina, Monoclinic Zirconia, amorphous silica and tetragonal zirconia respectively. Non crystalline and crystalline phase contents are presented in Table 5. The $\mathrm{m}-\mathrm{ZrO}_{2}$ and non crystalline content for the two different samples are almost equivalent2. The alumina content in AZS1 is higher than the one evaluated in the other sample.

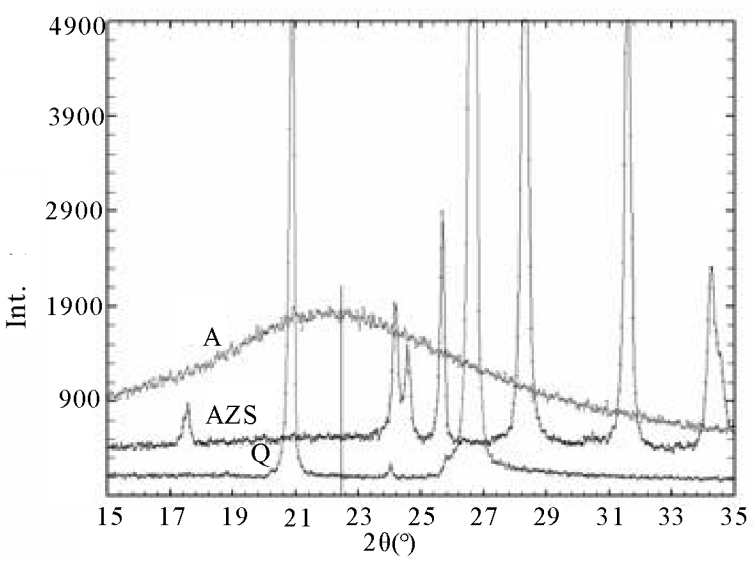

Figure 1. Crystalline quartz, amorphous silica and AZS1 sample diffractogram between $15^{\circ}-35^{\circ}$.

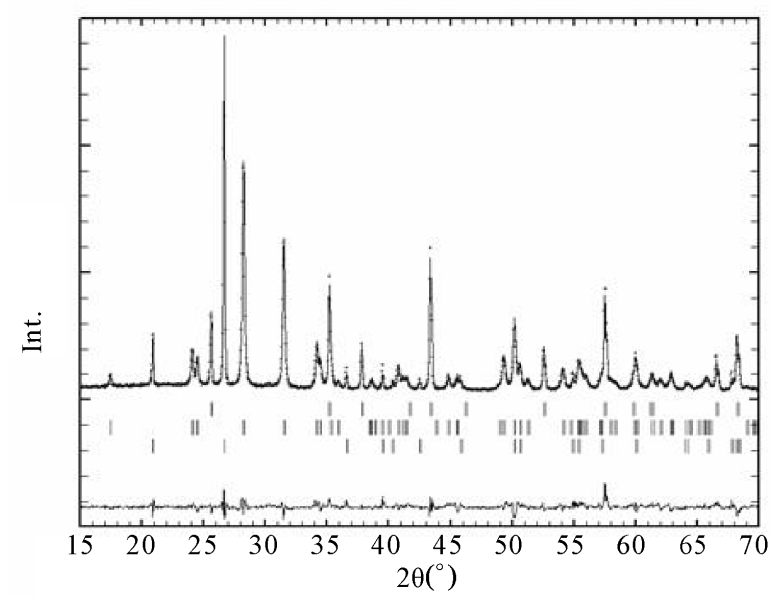

Figure 2. Rietveld refinement of sample AZS2 with crystalline quartz as internal standard.

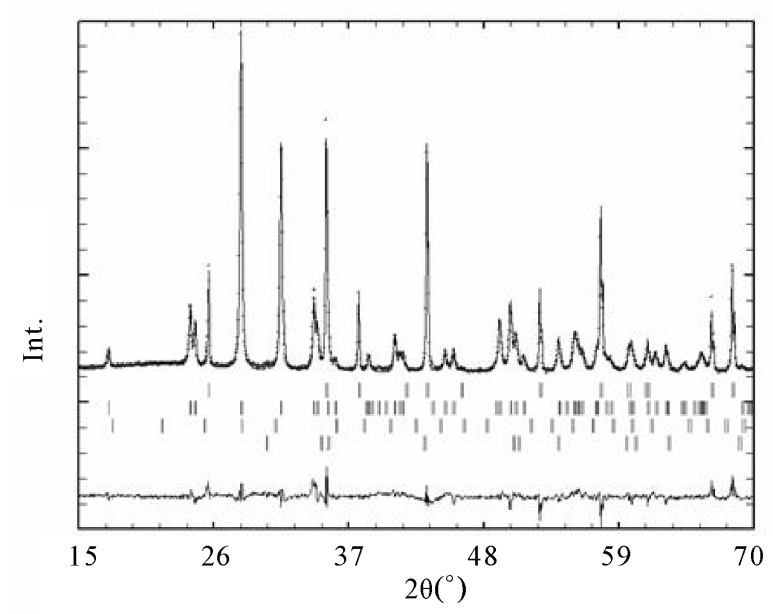

Figure 3. Rietveld refinement of sample AZS1 with the Le Bail model. 


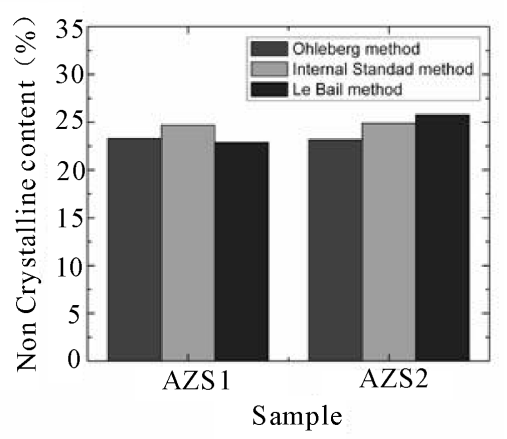

Figure 4. Comparison of the non crystalline content evaluation by the three applied methods.

\section{Summary}

The quantification results are compared in Figure 4 (bar chart). Although the three methods are based in completely different principle, their results are equivalent, with differences below 3\% for the studied material from two different samples, showing that the three models are adequate for the studied system, moreover the results match with the results provide by the material supplier (Table 1). In fact the results for the three applied methods are slightly higher.

Although the simplicity of Ohlberg method, it can be applied only for materials that do not present diffraction lines in $2 \theta=22.5$, and this method do not provides information about the other crystalline phases.

A complete phase quantification (crystalline and non crystalline) can be carried out by both Rietveld refinement based methods, but the Lebail model is recommendable because it is not necessary to contaminate the sample with the addition of the internal standard and it could be easily incorporated to a routinely Rietveld phase quantitative analysis without any increase in the number of $\mathrm{X}$ ray diffractograms.

\section{REFERENCES}

[1] G. Duvierre, E. Sertain and A. Rebert, "Advantages of Using High Zirconia Refractories in Lead Crystal Glass Electricfurnaces," Glass Technology, Vol. 34, No. 5, 1993, pp. 181-186.

[2] P. C. Ratto, "Réfractaires Electrofondus du Systeme AZS: Différentes Méthodes de Fabrication Oxydantes et Leurs Impacts sur le Comportement du Réfractaire en Service,” Verre, Vol. 8, No. 3, 2002, pp. 22-27.

[3] E. Lataste, "Comportement Mecanique et Endommagement de Refractaires Electrofondus sous Sollicitation Thermomecanique,” Ph.D. Dissertation, INSA de Lyon, 2005.

[4] S. Yamamura, M. Kitano and Y. Kakimoto, "An Integrated Approach to Optimum Furnace Design,” Glass In- ternational, Vol. 30, No. 1, 2007, pp. 40-41.

[5] J. Zborowski, "Some Aspects of Characterization of the Refractories for Glass Contact," Proceedings of the Unified International Technical Conference on Refractories: the 9th Biennial Worldwide Congress on Refractories, 2006, pp. 690-694.

[6] S. M. Winder, K. R. Selkregg and A. Gupta, "Update on Selection of Refractories for Oxy-Fuel Glass-Melting Service," Ceramic Engineering and Science Proceedings, Vol. 20, No. 1, 1999, pp. 81-105.

[7] S. M. Ohlberg and D. W. Strickler, "Determination of Percent Crystallinity of Partial Devitrified Glass by X-Ray Diffraction," Journal of the American Ceramic Society, Vol. 45, No. 4, 1962, pp.170-171. doi:10.1111/j.1151-2916.1962.tb11114.x

[8] J. P. Willams, G. B. Carrier, H. J. Holland and F. J. Farncomb, "The Determination of the Crystalline Content of Glass-Ceramics,” Journal of Materials Science, Vol. 2, No. 6, 1967, pp. 513-520. doi:10.1007/BF00752217

[9] S. Morimoto, "Phase Separation and Crystallization in the System $\mathrm{SiO}_{2}-\mathrm{Al}_{2} \mathrm{O}_{3}-\mathrm{P}_{2} \mathrm{O}_{5}-\mathrm{B}_{2} \mathrm{O}_{3}-\mathrm{Na}_{2} \mathrm{O}$ Glasses," Journal of Non-Crystalline Solids, Vol. 352, No. 8, 2006, pp. 756-760. doi:10.1016/j.jnoncrysol.2006.02.007

[10] H. M. Rietveld, "A Profile Refinement Method for Nuclear and Magnetic Structures,” Journal of Applied Crystallography, Vol. 2, No. 2, 1969, pp. 65-71. doi:10.1107/S0021889869006558

[11] R. A. Young, "The Rietveld Method,” International Union Crystallography, Oxford University Press, Oxford, 1993.

[12] D. L. Bish and S. Howard, "Quantitative Phase Analysis Using the Rietveld Method," Journal of Applied Crystallography, Vol. 21, No. 2, 1988, pp. 86-91. doi:10.1107/S0021889887009415

[13] N. V. Y. Scarlett, I. C. Madsen, L. M. D. Cranswick, T. L. Edward Groleau, G. Stephenson, M. Aylmore and N. Agron-Olshina, "Outcomes of the International Union of Crystallography Commission on Powder Diffraction Round Robin on Quantitative Phase Analysis: Samples 2, 3, 4, Synthetic Bauxite, Natural Granodiorite and Pharmaceuticals," Journal of Applied Crystallography, Vol. 35, No. 4, 2002, pp. 383-400. doi:10.1107/S0021889802008798

[14] A. G. De La Torre, S. Bruque and M. A. G. Aranda, "Rietveld Quantitative Amorphous Content Analysis," Journal of Applied Crystallography, Vol. 34, 2001, pp. 196-202. doi:10.1107/S0021889801002485

[15] A. Le Bail, "Modelling the Silica Glass Structure by the Rietveld Method," Journal of Non-Crystalline Solids, Vol. 183, No. 1-2, 1995, pp. 39-42. doi:10.1016/0022-3093(94)00664-4

[16] L. Lutterotti, R. Ceccato, R. Dal Maschio and E. Pagani, "Quantitative Analysis of Silicate Glass in Ceramic Materials by de Rietveld Method,” Material Science Forum, Vol. 278-281, 1998, pp. 87-92. doi:10.4028/www.scientific.net/MSF.278-281.87

[17] C. R. Ward and D. French, "Determination of Glass 
Content and Estimation of Glass Composition in Fly Ash Using Quantitative X-Ray Diffractometry,” Fuel, Vol. 85, 2006, pp. 2268-2277. doi:10.1016/j.fuel.2005.12.026
[18] J. Rodríguez-Carvajal, "Recent Developments of the Program Fullprof," Newsletter in Commission on Powder Diffraction (IUCr), Vol. 26, 2001. 